\title{
Neurocognitive Effects of Self-Determined Choice and Emotional Arousal on Time Estimation
}

Christina J. Mueller, Franz Classe, Birgit Stürmer, Lars Kuchinke, and Christine Stelzel

International Psychoanalytic University, Berlin, Germany

ABSTRACT

Even though effects of emotion and motivation on cognition are well documented, the interaction of all three factors is rarely investigated. Here, we used electroencephalography (EEG) to examine the effects of self-determined choice-as an experimental manipulation of intrinsic motivation and emotional stimulus content on task preparation and engagement in a temporal production task. Behavioral results indicated a modulation of time processing depending on choice and emotional content. Underlying EEG signals revealed differential modulations by choice on the contingent negative variation (CNV) during task and response preparation and by emotional content on the late positive potential (LPP) in response to the onset of an emotional picture during temporal production. Also, we obtained preliminary evidence for interaction effects of choice and emotional content on the LPP. The feedback-related negativity (FRN) in response to information regarding temporal production success was also affected by interactions of choice and emotional content. These findings indicate that besides separate effects of motivation and emotion, there may be time windows during task engagement in which both factors jointly affect cognitive processing. These results are interpreted as dynamic modulations of attentional resource allocation.

\section{INTRODUCTION}

Much research has been devoted to factors that modulate behavioral performance in cognitive tasks. Emotional (Dreisbach \& Goschke, 2004; Vuilleumier, 2005) and motivational effects (Engelmann \& Pessoa, 2007; Huebner \& Schlosser, 2010; Paschke et al., 2015) on cognitive performance have been shown repeatedly. Giving a detailed overview on both, Pessoa (2009) illustrates how emotion and motivation might affect cognitive performance jointly: emotional stimuli are thought to capture attentional resources such that task-relevant emotional stimuli are prioritized compared to other stimuli. However, when affective stimuli are not task relevant, they impair behavioral performance by withdrawing attentional resources from cognitive tasks. The effect of motivational stimulus characteristics seems partly similar to that of emotional stimuli in the sense that they also modulate attentional processes. For example, reward motivation seems to affect sensitivity in stimulus detection (Engelmann et al., 2009) but also distractor inhibition (Paschke et al., 2015) via efficient orientation of attentional resources in the face of rewarding stimuli. How emotion and motivation modulate cognitive performance jointly is rarely studied even though both seem to affect performance via similar attentional processes. Here, we aimed to contribute to this line of research with an electroencephalography (EEG) study on motivation-emotion interactions on performance in a temporal production task-a task that

Corresponding author: Christine Stelzel International Psychoanalytic University Stromstr. 1, 10555 Berlin, Germany.

Email: christine.stelzel@ipu-berlin.de 
appears well-suited to capture preparatory and stimulus-related attentional processes and, in addition, has high potential to elicit intrinsic motivation to perform well (Murayama et al., 2013).

While motivational effects are often studied by manipulating specific stimulus rewards, here, we were specifically interested in the effect of intrinsic motivation, which can be studied via offering choice options (Ryan \& Deci, 2000). Making self-determined choices is important to most individuals in situations including education, work, health, or leisure (Cordova \& Lepper, 1996; Ng et al., 2012; Van den Broeck et al., 2008). Choice has been related to positive affect, subjective well-being, and general health (Bandura \& Wood, 1989; Leotti et al., 2010; Ryan \& Deci, 2000), and ultimately improves subsequent task performance compared to situations where tasks are assigned by someone else or a chosen task is rejected (Patall et al., 2008). These effects are typically explained in terms of choice-induced higher intrinsic motivation, which results in higher effort and persistence in task engagement and thus better performance (Cerasoli et al., 2014). Besides effects on cognitive task performance, effects of choice also have been shown with regard to the modulation of emotional processing, for example, in terms of adaptive down-regulation of negative affect in stressful situations (Maier \& Watkins, 2010; Salomons et al., 2007). These effects have been explained in terms of beneficial motivational and affective signals associated with a desirable state of perceived autonomy or control (Leotti et al., 2010; Ly et al., 2019; Ryan \& Deci, 2000), but little is known about the dynamic interactions of motivational and affective signals during task engagement.

Recent neuroscientific studies have begun to specify the neural mechanisms underlying performance improvements after self-determined choices. For example, in an EEG study, Legault and Inzlicht (2013) found that perceived autonomy of task choice improved task performance and was associated with larger amplitudes of the error related negativity (ERN), an event-related potential (ERP) that is most likely elicited in the anterior cingulate cortex (ACC) when participants notice that they made a mistake (Dehaene et al., 1994; Holroyd \& Coles, 2002). The authors hypothesized that perceived autonomy increases performance via enhanced receptivity to self-regulation failure and should, therefore, be evident in attention to not only errors, but also to negative feedback. While Legault and Inzlicht (2013) found evidence for modulated error responses in ERN amplitudes by autonomy, Murayama et al. (2013) studied the effect of self-determined choice on negative feedback processing. They used functional imaging to show differential modulations of value-based signals in the ventromedial prefrontal cortex (vmPFC) after failure feedback depending on whether or not participants were given a task-irrelevant choice option beforehand. While the cognitive task was always the same (participants had to stop a stop watch as accurately as possible after $5 \mathrm{~s}$ ), they were allowed to choose the design of the stop watch on some trials, but not on other trials. VmPFC signals were only reduced after failure feedback when no choice was given to participants, while they remained unchanged in the choice condition. In addition to these modulatory effects on task-related outcome processing, Leotti and Delgado (2011) showed that even anticipation of free choice seemed to be inherently positive, as reflected in increased activity in motivational-affective circuits including the ventral striatum. Likewise, restricting choice is experienced as aversive and stressful, modulating task engagement and emotional regulation substantially (Cosme et al., 2018; Deci et al., 1989).

While anticipating a self-determined choice and processing feedback afterwards are important components to motivational modulations of task engagement, different aspects of information processing in the task per se also might change depending on choice. This includes cognitive aspects, such as the preparation for and initiation of actual task performance, the processing of task-relevant stimuli, as well as response-related processes (Forstmann et al., 2006; Forstmann et al., 2007; Orr \& Banich, 2014). Besides the above-mentioned effects on vmPFC activation, Murayama et al. (2013) additionally found selfdetermined choice to have a small effect on activity in the presupplementary motor area (preSMA) during task initiation, consistent with the role of this region in voluntary action generation (Haggard, 2008; Passingham et al., 2010). In addition, emotional aspects of the task might be processed differently depending on the motivational state elicited by choice versus no choice (Rothermund et al., 2011).

In the present study, we used EEG to examine the time course of choice effects on cognitive task and feedback processing as well as interactions with processing of emotional content of task-related stimuli. For this, we developed a new paradigm which allowed us to demonstrate the time course of choice effects on task processing with neutral and emotional stimuli. As the cognitive task, we used a temporal production task where participants are instructed to produce a defined time interval by making a response via a button press (Matthews \& Meck, 2016). A number of stimulus characteristics have been discussed to influence time production, among them attentional processes. For example, subjective duration is experienced as longer (meaning temporal production is shorter) when stimuli are processed with high attentional resources. As suggested by Pessoa (2009), both motivation and emotion influence stimulus processing via attentional modulations and should, therefore, be evident in temporal production manipulations. Performance in a similar task has previously been shown to be modulated by choice (Murayama et al., 2013) and various studies indicated that emotional context affects time perception (Droit-Volet et al., 2004; Droit-Volet \& Gil, 2009; Droit-Volet \& Meck, 2007). Also, this task is well-suited to elicit intrinsically motivated task performance (Csikszentmihalyi et al., 2005). Participants were presented with either neutral or negative images and were meanwhile asked to produce a certain time interval (i.e., 3 seconds) by pressing a button. After picture onset, the late positive potential (LPP), which is known to be sensitive to emotional and attentional processes (Cuthbert et al., 2000; Olofsson et al., 2008) was investigated. With the button press, the image disappeared and participants received feedback regarding their produced time. After its onset, the participants' feedback responses were investigated using feedback related negativity (FRN), which is sensitive to performance differences (positive as compared to negative feedback; Hajcak et al., 2006). Critically, before this task, participants could choose between four categories of images they wanted to see in 
the current trial (e.g., humans, actions, nature, etc.). This choice was either approved in half of the trials or denied in the other half and participants were informed about another category they would be presented with. Since choice was expected to be intrinsically rewarding (Ly et al., 2019) and has been shown to be associated with activity in motivational affective circuits (Leotti \& Delgado, 2011), we expected a positive effect of choice on task preparation and task engagement during the temporal production task. With respect to task preparation, we investigated the pre-stimulus contingent negative variation (CNV) in the time window between notification of acceptance or rejection of choice and before picture onset. The CNV has been linked to preparation for an upcoming task in previous studies (Karayanidis et al., 2003; Van Boxtel \& Brunia, 1994). Additionally, we measured the pre-response CNV to test for modulations of response preparation processes previously associated with the CNV in time estimation tasks (van Rijn et al., 2011). Since performance improvement due to choice has been reported before (Cerasoli et al., 2014), we expected choice to interact with the formerly mentioned ERP components during emotion picture processing while performing the task (LPP and pre-response CNV) and during feedback processing (FRN).

Therefore, by measuring EEG during choice and task processing, we were able to test the following hypotheses: (a) self-determined choice enhances task preparation, as reflected in greater $\mathrm{CNV}$ amplitudes compared to denied trials; (b) effects of choice interact with emotional processing with respect to attentional processes during task performance, as reflected in the stimulus-related LPP; and (c) selfdetermined choice enhances the processing of performance feedback, as reflected in the FRN.

\section{MATERIALS AND METHODS}

\section{Participants}

The group of 19 participants (11 females), all students between 18 and 32 years of age $(M=22.89, S D=3.75)$ was recruited via university email lists and existing databases to take part in the study. Only participants who fulfilled the requirements of having no history of neurological or psychiatric disorder and having normal or corrected-to-normal vision took part in the study and were endorsed with either course credit or $€ 25$ allowance. Written informed consent was obtained from all participants prior to the study, after thorough briefing on the procedure of the experiment. The study was approved by the ethics committee of the International Psychoanalytic University and conducted in accordance with the Declaration of Helsinki. Data from two additional participants were discarded because they did not follow the task instructions properly.

\section{Procedure}

After filling out a questionnaire regarding demographic data and their current state, EEG and EOG electrodes were applied. Participants were then led into the EEG laboratory where they were seated in front of a 24 in. computer screen. In addition to a keypad, six buttons below the screen were arranged on the table as follows (see Figure 1): four "choice buttons" were arranged in a $2 \times 2$ square. On either side of the square, an additional "temporal production button" was positioned with some distance to the square of four buttons. The button on the left side could easily be reached by the participants' left hand and the button on the right side of the square could easily be reached with the right hand. Before the main experiment, participants were asked to passively watch the pictures on the computer screen, which they were told they would encounter again in the main experiment. Each picture corresponded to one of eight different categories: "street," "animal," "human," "action," "nature," "building," "vehicle," or "utensil” and depicted photos of objects, (non)human beings, or scenes. Eight pictures were presented for each category, resulting in 64 pictures total. Four of the pictures in each category were selected from the International Affective Picture System (IAPS; Lang et al., 1993) or the Nencki Affective Picture System (Marchewka et al., 2014) as being neutral, with medium valence and low arousal (valence: $M=5.10, S D=0.60$; arousal: $M=3.05$, $S D=0.57$ ), and four as being negative, with low valence and medium to high arousal (valence: $M=2.51, S D=0.51$; arousal: $M=6.16, S D=$ 0.74 ). For each picture category, the category name was presented first for $1500 \mathrm{~ms}$, followed by a sequence of the eight pictures corresponding to the category, with each picture being visible on screen for 1000 ms. After each picture, a fixation cross was shown for $1500 \mathrm{~ms}$. The order of pictures within a category was randomized, as was the order of categories.

After becoming acquainted with the stimulus material, participants practiced the cognitive task to be performed in the main experiment. The task consisted of producing a time interval of $3 \mathrm{~s}$ as accurately as possible without any external aids. That is, cell phones and watches were not present during the experiment. Other than that, no instructions were given regarding internal strategies. In the practice blocks, each trial started with the presentation of a white cross on a black screen for $250 \mathrm{~ms}$ followed by a white circle (about 4.5 inches in diameter) on a black screen. The circle's appearance marked the starting point for the temporal production that was ended by a button press once participants thought the $3 \mathrm{~s}$ interval to be over. After the button press, the circle disappeared and participants received visual feedback about their produced time interval. If a button press was not recorded after $6 \mathrm{~s}$, the circle disappeared and a new trial began. The practice part of the experiment consisted of two parts: two blocks of 22 trials each were performed with the left and two with the right index finger. The order of the relevant response hand was counterbalanced across participants. Practice for each hand preceded the main experiment. For each response hand, RT means and SDs were determined and used as feedback criterion in the main experiment (see below).

In the subsequent main experiment, participants also performed a temporal production task. However, each main trial consisted of two parts: (a) a choice part and (b) a temporal production part. An example trial is depicted in Figure 1.

Each trial started with a fixation cross in the center of the screen for $500 \mathrm{~ms}$ followed by the presentation of a $2 \times 2$ square compatible with the arrangement of the choice buttons. Each part contained one 
TABLE 1.

Means, Minimum, Maximum, and SDs for the Frequency of Category Presentation

\begin{tabular}{ccccc}
\hline \multirow{2}{*}{ Category Self } & \multicolumn{2}{c}{ Denied } \\
\cline { 2 - 5 } & $M($ Min; Max $)$ & $S D$ & $M($ Min; Max $)$ & $S D$ \\
\hline street & $14.4\left(6.3 ; 33.9^{*}\right)$ & 5.7 & $10.8(4.5 ; 15.5)$ & 2.5 \\
animal & $13.2(5.4 ; 21.1)$ & 5.0 & $12.6(6.4 ; 20.0)$ & 4.0 \\
human & $12.4\left(5.4 ; 38.4^{*}\right)$ & 7.3 & $11.7(4.5 ; 20.0)$ & 3.6 \\
action & $11.3(7.1 ; 16.7)$ & 2.5 & $13.8(8.2 ; 21.8)$ & 3.2 \\
nature & $12.6(1.7 ; 25.0)$ & 5.8 & $13.0(7.8 ; 17.3)$ & 2.7 \\
building & $12.2(3.8 ; 22.3)$ & 4.1 & $11.9(4.5 ; 18.9)$ & 3.5 \\
vehicle & $13.2(2.7 ; 20.2)$ & 4.9 & $12.4(7.3 ; 19.1)$ & 3.3 \\
utensil & $10.6(0.9 ; 21.6)$ & 4.4 & $13.8(5.5 ; 18.8)$ & 3.5 \\
\hline
\end{tabular}

Note. For the SELF condition this corresponds to the distribution of participants' choices while for DENIED condition it is the pseudorandom experimental distribution based on the non-selected categories of the participants.

${ }^{*}$ One participant showed a strong preference for the categories street / human (greater 2 SDs than mean choice rate). Exploratory exclusion of this participant from all behavioral and EEG analyses did not change the obtained results pattern. The participant therefore remained included.

of the eight category names of which participants had seen the pictures prior to the practice blocks. Categories were randomly selected from the set of eight category names. In the $2 \times 2$ square, each category name could only appear once in a given selection. Participants were instructed to choose their preferred category by pressing the spatially corresponding response button. Category names were displayed until participants made their choices, but maximally for $4000 \mathrm{~ms}$. The choice was followed by a fixation cross for $500 \mathrm{~ms}$, after which participants were given feedback on the chosen category for the upcoming temporal production. Their choice of category was either accepted ("self"), as indicated by framing the chosen category name in green color, or rejected ("denied"), as indicated by framing a randomly assigned category name in yellow color. The frame was displayed for at least 1000 $\mathrm{ms}$, indicating which category of picture was about to be shown in the upcoming temporal production part of the trial. If a participant made the category choice faster than $4000 \mathrm{~ms}$, the remaining amount of time (4000 ms - choice time) was added to the display time of the chosen or assigned category. Therefore, the total choice part always took the same amount of time $(5500 \mathrm{~ms})$. If no option was chosen, the trial was aborted and participants were asked to respond next time. Frequency of self and denied trials was approximately equal (denied: $49.67 \%$, range $=110-112$ trials; self: $50,32 \%$, range $=112-114$ trials). The order was pseudorandomized across the experiment, with the restriction that each condition could appear maximally three times in a row and that transition frequencies were equal. Descriptive statistics on category distributions are presented in Table 1.

After the choice process and a subsequent fixation cross $(1500 \mathrm{~ms})$, the temporal production part of the trial started with the presentation of a neutral or negative picture corresponding to the formerly indicated category. Frequency of neutral versus negative trials was approximately equal (50.48\% neutral; $49.52 \%$ negative) and equally distributed across the self and denied conditions. The order of negative versus neutral pictures was pseudorandomized across the experiment, with the restriction that each condition was repeated maximally three times in a row and that transition frequencies were equal. The picture onset marked the starting point for the temporal production and participants finished their estimation of the $3 \mathrm{~s}$ interval with a button press. After the button press, the picture disappeared and participants were presented with a fixation cross for $500 \mathrm{~ms}$, followed by feedback regarding the accuracy of their temporal production that was also shown for $500 \mathrm{~ms}$. If the deviation of the temporal production in a given trial exceeded $3000 \mathrm{~ms}+/$ - a cut-off value, feedback regarding the actually produced time was shown in red color, indicating a large deviation. If the deviation from $3000 \mathrm{~ms}$ was within the range of $3000 \mathrm{~ms}+/$ - a cut-

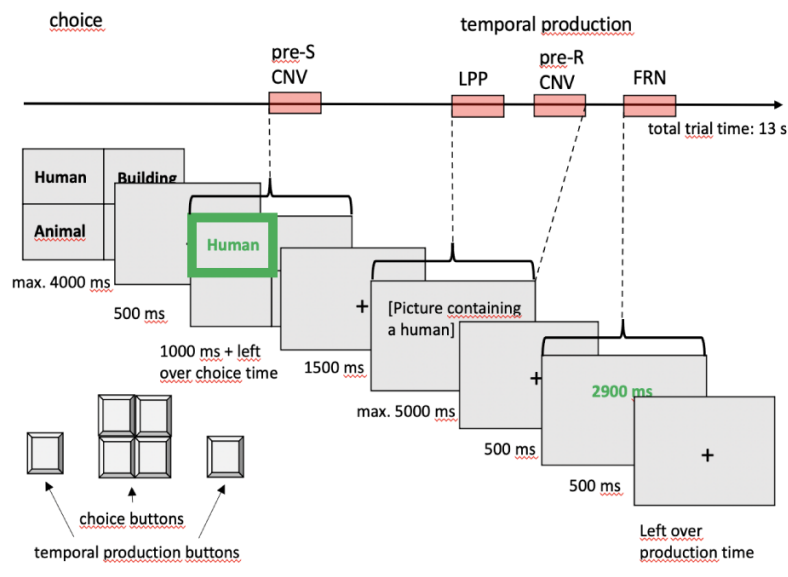

FIGURE 1.

Example trial timing. A green frame during the choice part indicates a self trial in which the participant's choice was approved. In denied' trials, another category name was framed in yellow. Temporal production of $3 \mathrm{~s}$ starts with picture presentation (neutral or negative) and is followed by feedback of RT. pre-S: pre-stimulus; pre-R: pre-response. 
off value, feedback was shown in green color, indicating a small deviation. The corresponding cut-off values were individually determined for each participant through analysis of the response hand-specific practice block. Means and SDs of the deviances from $3000 \mathrm{~ms}$ in the practice block were computed and mean deviation +/- $1 S D$ served as the upper and lower cut-off values for feedback.

If participants did not take the full range of $5000 \mathrm{~ms}$ to produce the time interval of $3 \mathrm{~s}$, a fixation cross was shown after feedback presentation for $5000 \mathrm{~ms}$ minus the produced duration. Thus, the temporal production part of the trial always took $7500 \mathrm{~ms}$. Together with the choice process part, each trial took 13 s. If participants exceeded 5000 ms without pressing a button or indicated their answer pressing a wrong button, the trial was aborted.

Participants completed 224 trials in the main experiment that were split up into 14 blocks of 16 trials each. Half of the blocks were performed using one specific response hand followed by another seven blocks performed using the other hand, both separated by a 5 min break while all other blocks were separated by short self-paced breaks. The first block of each response hand was preceded by two additional practice trials that were not included in the analysis. In each block, at least six trials were self or denied and at least six trials were negative or neutral.

After completion of the main part of the experiment, participants were asked to rate the pictures on two 9-point Likert scales. First, they were asked to indicate the pleasantness of a given picture $(1=$ very unpleasant and $9=$ very pleasant). Then, they were asked to indicate how arousing they found a given picture $(1=$ not arousing and $9=$ very arousing $)$.

All instructions and stimuli were presented and manual responses were recorded via Presentation software https://www.neurobs.com/.

Lastly, participants filled out two motivational questionnaires, the HAKEMP 90 (Kuhl, 1990) targeting the control of actions after success and failure, and the Need for Cognition questionnaire, measuring engagement and joy in thinking (Cacioppo et al., 1996). These are not considered in the present analyses, but will be pooled with other data sets for individual differences analyses.

\section{EEG RECORDINGS}

Electroencephalography recordings were obtained using Brain Vision Recorder (Brain Products, Munich, Germany) and took place in a sound shielded laboratory at the International Psychoanalytic University Berlin. The EEG data were measured with $62 \mathrm{Ag}-\mathrm{AgCl}$ electrodes and placed on the scalp with a cap (EASYCAP GmbH) according to the international 10-20 system. Electrode AFz served as ground electrode and reference electrodes were placed on both mastoids. Measured electrodes were: Fp1, Fp2, Fpz, AF3, AF4, AF7, AF8, Afz, F1, F2, F3, F4, F7, F8, F9, F10, Fz, FC1, FC2, FC3, FC4, FC5, FC6, FT9, FT10, FCz, C3, C4, C5, C6, T7, T8, Cz, CP1, CP2, CP3, CP4, CP5, CP6, CPz, TP9, TP10, P3, P4, P5, P6, P7, P8, P9, P10, Pz, PO3, PO4, PO7, PO8, PO9, PO10, Poz, O1, O2, Oz, and Iz. The EEG signal was recorded at a frequency of $500 \mathrm{~Hz}$ and electrode impedances were kept below $5 \mathrm{k} \Omega$. Two additional electrodes were used to measure electroocular activity, with one electrode measuring activity below the right eye for vertical eye movements and one electrode measuring horizontal eye movements by being placed on the right canthus.

\section{EEG DATA PROCESSING}

The raw EEG data were analyzed using Brain Vision Analyzer software (Brain Products, Munich). A low-cutoff filter of .01 Hz was used along with a high-cutoff filter of $40 \mathrm{~Hz}$ and a notch filter of $50 \mathrm{~Hz}$. Data were rereferenced to linked mastoids. A manual raw data inspection was carried out in order to exclude muscular artefacts. Afterwards, an ocular correction independent component analysis was carried out in order to control the data for eye blinks and eye movements. Data of all electrodes that were relevant for analyses (FCz, Cz, PO3, PO4, Poz, PO7, and PO8) were then submitted to an automatic raw data inspection that excluded all intervals with amplitudes above $90 \mu \mathrm{V}$ and below $-90 \mu \mathrm{V}$.

Data concerning the pre-stimulus CNV were calculated for the choice part. For this, data were cut into segments of $3000 \mathrm{~ms}$ with 1000 ms before the visual cue on whether the subjects' category choice was accepted or rejected and $2000 \mathrm{~ms}$ in the interval thereafter. Segments were baseline corrected to the $500 \mathrm{~ms}$ interval before the visual feedback regarding the choice was shown. All self trials in which participants' choices were accepted and all denied trials in which their choices were rejected were averaged separately to calculate mean time courses and mean amplitudes. Mean amplitudes of electrode $\mathrm{Cz}$ where the CNV is usually measured (Kropp et al., 2000) were visually inspected and showed a typical CNV from $500 \mathrm{~ms}$ on (see Figure 3). Therefore, we exported for analysis the time interval between 500 and $700 \mathrm{~ms}$ after the visual feedback regarding the choice was given.

Data concerning the LPP were calculated for temporal productions. For this, EEG data were segmented into bins from -200 until $1000 \mathrm{~ms}$ with respect to the appearance of the affective picture. After a baseline correction to the pre-stimulus interval $(-200-0)$, data were averaged separately for self and denied trials as well as for negative and neutral pictures. Due to visual inspection of posterior electrodes (i.e., PO3, PO4, POz, PO7, and PO8) where the P3b component has been typically located (Polich, 2007) and turns into the LPP (Olofsson et al., 2008), mean amplitudes of these electrodes were exported and clustered by means of averaging across electrodes for eight $50 \mathrm{~ms}$ intervals between 300 and 700 ms post stimulus.

Data concerning the preresponse CNV were segmented -2200 until $500 \mathrm{~ms}$ with respect to the response in the time production task. The interval -2200 to $-2000 \mathrm{~ms}$ was used as baseline, data were averaged separately for self and denied trials as well as for negative and neutral pictures. As visual inspection did not show a clear CNV with a maximum at $\mathrm{Cz}$, mean amplitudes of six midline electrodes $(\mathrm{Fz}, \mathrm{FCz}$, $\mathrm{Cz}, \mathrm{CPz}, \mathrm{Pz}$, and $\mathrm{POz}$ ) were exported for eight $100 \mathrm{~ms}$ time windows from -800 to $0 \mathrm{~ms}$ to explore preresponse $\mathrm{CNV}$ effects.

Data concerning the FRN were segmented from -200 until 1000 ms with respect to the appearance of the feedback information regarding the accuracy of temporal production. The prefeedback stimulus time interval $(-200--0)$ was used as baseline. Data were averaged separately for self and denied trials, negative and neutral pictures, 
and positive or negative feedback. Individual FRN amplitudes and latencies for these averages were then computed from base-to-peak on electrode FCz according to Holroyd et al. (2003), as suggested by Hajcak et al. (2006). Following their algorithm, a positivity in each averaged subset was first identified via a peak detection in the interval between 160 and $240 \mathrm{~ms}$ after feedback was shown. The latency of this positivity was taken as onset of the FRN. In the subsequent time window from the peak of the positivity until $325 \mathrm{~ms}$ after feedback onset, another peak detection was carried out in order to identify the latency of the most negative peak-the FRN. The amplitude was then computed as difference between amplitude at component onset and at its maximum peak.

\section{DATA ANALYSES}

Ratings. To ensure that participants experienced stimuli as belonging to the emotional category they were preassigned to, paired $t$ tests were calculated to compare mean valence and mean arousal ratings for all shown pictures.

Behavioral data. Temporal production data were analyzed in terms of total RTs as well as mean deviations (absolute values) from the target time of $3000 \mathrm{~ms}$. Outlier corrections were applied to RTs, excluding trials below and above $1 S D$ per subject, per condition, and per response hand. These trials were also excluded for the analysis of temporal production deviations. This rather strict outlier criterion was used for two reasons. First, due the rather long time production interval of $3000 \mathrm{~ms}$, we expected within-trial attentional fluctuations not related to the experimental manipulations, which might affect estimated means unsystematically. Second, the analysis of the FRN was based on a $1 S D$ feedback criterion to acquire a decent amount of negative feedback trials. Thus, for the behavioral data, analyses were restricted accordingly.

For both outcome variables, repeated-measures analyses of variance (ANOVAs) with choice (self vs. denied) and emotional content (neutral vs. negative) as within-subject factors were performed. In addition, the number of missed responses and slow responses, as defined via the cut-off value form the practice block were analyzed.

EEG data. For the pre-stimulus CNV, exported mean amplitudes of electrode $\mathrm{Cz}$ from 500 till $700 \mathrm{~ms}$ after choice feedback presentation where emotional content was not yet predictable were submitted to paired t tests (self vs. denied). For the LPP cluster, repeated-measures ANOVAs with choice (self vs. denied) and emotional content (neutral vs. negative) were carried out on all exported time windows (300-350 ms; 350-400 ms; 400-450 ms; 450-500 ms; 500-550 ms; 550-600 ms; $600-650 \mathrm{~ms}$; and 650-700 ms). For the preresponse CNV, repeatedmeasures ANOVAs with choice (self vs. denied), emotional content (neutral vs. negative), and electrode ( $\mathrm{Fz}, \mathrm{FCz}, \mathrm{Cz}, \mathrm{CPz}, \mathrm{Pz}$, and $\mathrm{POz}$ ) were carried out on all exported time windows $(-800$ to $-700 \mathrm{~ms}$, -700 to $-600 \mathrm{~ms},-600$ to $-500 \mathrm{~ms},-500$ to $-400 \mathrm{~ms},-400$ to -300 $\mathrm{ms},-300$ to $-200 \mathrm{~ms},-200$ to $-100 \mathrm{~ms}$, and -100 to $0 \mathrm{~ms}$ ). Both analyses were tested for robustness, controlling for multiple comparisons using the Benjamini and Hochberg's (1995) procedure to control for false discovery rate. For the FRN, repeated-measures ANOVAs with choice (self vs. denied), emotional content (neutral vs. negative), and feedback (positive vs. negative) were carried out on latencies and amplitudes that were identified via the base-to-peak detection method as described above.

\section{RESULTS}

\section{Rating Results}

Pictures in the negative category were confirmed to appear more negative regarding their valence $(M=2.60, S E=.19)$ compared to pictures in the neutral category $(M=6.05, S E=.16), t(16)=14.26, p$ $<.001, d=3.46)$. Picture ratings additionally differed significantly regarding arousal, which was rated higher for negative $(M=6.57, S E=$ .32) compared to neutral pictures $(M=2.58, S E=.18) t(16)=-12.41$, $p<.001, d=3.01)$.

\section{Behavioral Data}

Participants made their choices of category on average after 1187.46 $\mathrm{ms}(S E=81.47)$.

During temporal production on average, participants made $80.1 \%$ responses that were within the individual cut-off boundaries of $+/-1$ $S D(S E=7.9 \%)$ and prompted feedback in green color. In $18.4 \%$ (SE $=1.9 \%$ ) of the trials, participants made responses that lay outside the cut-off boundaries but did not exceed the limit of $5 \mathrm{~s}$. On these trials, feedback was indicated in red color.

While absolute temporal production times revealed no general modulation depending on choice, $F(1,18)=0.001, p=.976, \mathrm{n}_{\mathrm{p}}{ }^{2}<.001$, or emotional content, $F(1,18)=3.62, p=.073, \mathrm{n}_{\mathrm{p}}{ }^{2}=.168$, a significant interaction of both factors, $F(1,18)=6.08, p=.024, \mathrm{n}_{\mathrm{p}}{ }^{2}=.252$, re-

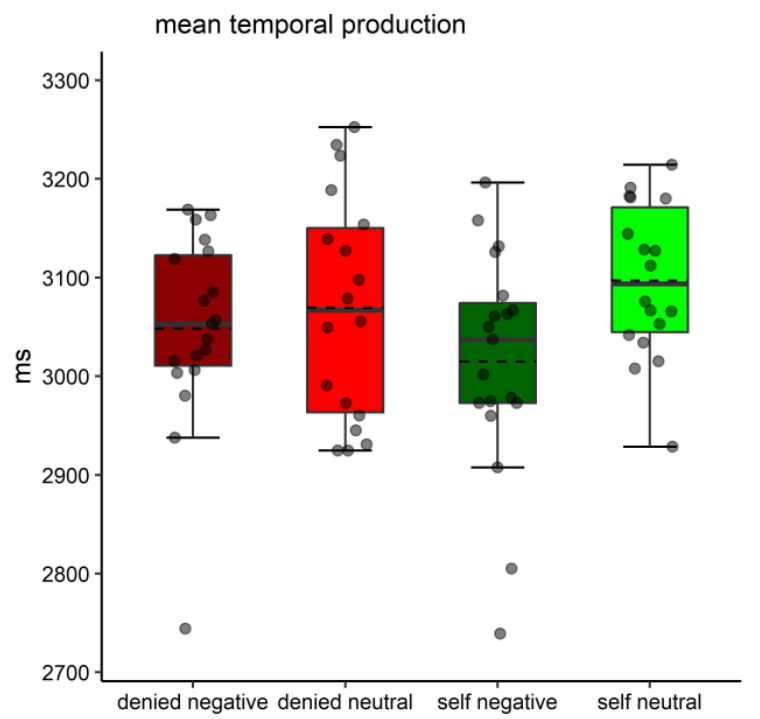

FIGURE 2.

Mean temporal productions for target interval of $3 \mathrm{~s}$ (solid line depicts medians, dashed line depicts means, error bars define outliers with values greater than 1.5 interquartile range of median) 
vealed a differential modulation (see Figure 2): Temporal productions were generally shorter for negative compared to neutral pictures in the self condition, $t(18)=2.99, p=.008, d=.525$, an effect that was not present in the denied condition, $t(18)=0.25, p=.805, d=.028$. Thus, emotional modulation of temporal production was only present when participants made self-determined choices but not when their choices were denied. In order to examine the effect of self-determination on performance, we additionally computed post-hoc tests of the interaction investigating choice differences separately for both emotion conditions. For neutral pictures, no differences in performance were evident between self $(M=3076.08, S E=27.25)$ and denied trials $(M=$ 3043.46, $S E=36.27), t(18)=1.598, p=.127, d=.37$. For negative pictures, a trend for a performance difference was evident in absolute temporal productions, $t(18)=-2.05, p=.055, d=.47$, with self-determined choices $(M=3014.94, S E=26.16)$ being closer to the target time of $3000 \mathrm{~ms}$ compared to denied-choice trials $(M=3048.34, S E=22.74)$.

Concerning the absolute deviation of participants' temporal productions from the target time, no significant modulation depending on factors choice, emotional content, or their interaction was present. However, a trend for emotional content, $F(1,18)=4.251, p=.054, \mathrm{n}_{\mathrm{p}}{ }^{2}$ $=.191$, revealed slightly lower deviations for negative $(M=220.68 \mathrm{~ms}$, $S E=16.86)$ compared to neutral pictures $(M=237.80 \mathrm{~ms}, S E=16.86)$.

\section{EEG Data}

\section{PRESTIMULUS CNV}

Prestimulus CNV results revealed a significant modulation in the time interval after feedback regarding acceptance of choice was given (see Figure 3). Paired $t$ tests on mean amplitudes of electrode $\mathrm{Cz}$ revealed a significantly greater pre-stimulus $\mathrm{CNV}$ for self trials $(M=-1.13, S E=.45)$ compared to denied trials $(M=.34, S E=.60)$, $t(18)=-5.041, p<.001, d=.557$.

\section{LPP}

During temporal production, emotional content robustly modulated LPP amplitudes, an effect that was partly dependent on whether or not participants made self-determined category choices. Detailed results of the repeated-measures ANOVAs for the eight time intervals are displayed in Table 2, where main effects and interactions are reported. Post-hoc analyses of significant interactions are reported below. While no main effect of choice was evident in any of the investigated time windows, main effects of emotional content persisted from the early time window between 350 and 400 ms until the last investigated time window from 650 to $700 \mathrm{~ms}$, with most robust, corrected effects between 400 and $600 \mathrm{~ms}$. In all time windows, larger amplitudes were present in response to negative compared to neutral pictures (see time courses and exemplary bar plot in Figure 4). In addition, interaction effects of choice and emotional content were present in two time windows $(600-650 \mathrm{~ms}$ and $650-700 \mathrm{~ms}$ ) for which post-hoc paired t tests revealed that an effect of emotional content was only evident in self trials (600-650 ms: $t[18]=4.01, p=.001, d=.443 ; 650-700 \mathrm{~ms}: t[18]=4.04, p=.001$, $d=.477)$, with larger amplitudes in response to negative compared to neutral pictures, but not in denied trials $(600-650 \mathrm{~ms}: t[18]=$ $.941, p=.359, d=.146 ; 650-700 \mathrm{~ms}: t[18]=.877, p=.392, d=.135$ ). However, these interaction effects did not withstand correction for multiple comparison and thus should be interpreted with caution.

\section{PRERESPONSE CNV}

Preresponse CNV results of repeated-measures ANOVAs for the eight $100 \mathrm{~ms}$ time windows showed a significant main effect of choice for the time window -100 to $0 \mathrm{~ms}, F(1,18)=4.903, p=.04$. Post-hoc single comparisons of self versus denied at all six midline electrodes revealed a significant effect at $\mathrm{CPz}, t(18)=2.345, p=.031$, and $\mathrm{Pz}, t(18)$ $=3.158, p=.005$. Taking corrections for multiple comparisons into ac-
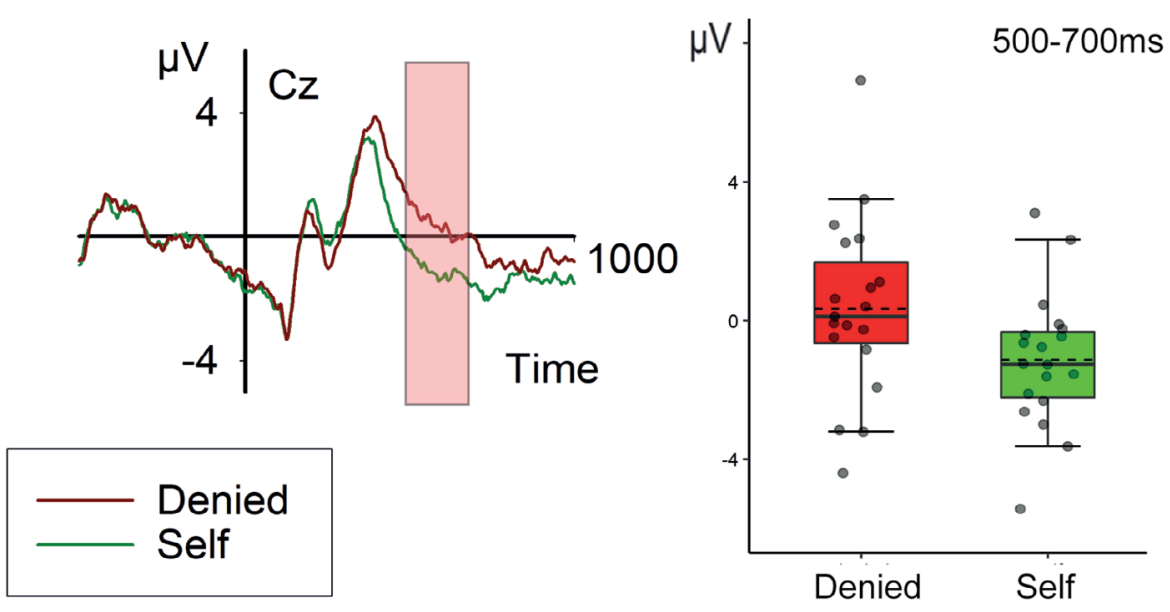

\section{FIGURE 3.}

Prestimulus contingent negative variation (CNV) results at electrode CZ, showing greater CNV for self compared to denied trials in the time window from 500-700 ms (red background). Box plot depicts medians (solid lines) and means (dashed lines), error bars define outliers with values greater than 1.5 interquartile range of the median. 


\begin{tabular}{|c|c|c|c|c|c|c|c|c|c|}
\hline \multirow{2}{*}{ Time } & \multicolumn{3}{|c|}{ Choice } & \multicolumn{3}{|c|}{ Emotional content } & \multicolumn{3}{|c|}{ Interaction } \\
\hline & $F$ & $p$ & $n_{p}{ }^{2}$ & $F$ & $p$ & $n_{p}{ }^{2}$ & $F$ & $p$ & $n_{p}{ }^{2}$ \\
\hline $300-350$ & 2.21 & .155 & .109 & .26 & 615 & .014 & 1.59 & .223 & .081 \\
\hline $350-400$ & .38 & .545 & .021 & 6.45 & $.021^{*}$ & .264 & 1.29 & .272 & .067 \\
\hline $400-450$ & 2.98 & 101 & .142 & 8.40 & $.010^{* * *}$ & .318 & 1.01 & .328 & .053 \\
\hline $450-500$ & 2.90 & 1.06 & .139 & 15.31 & $.001^{* * *}$ & .460 & .31 & .584 & .017 \\
\hline $500-550$ & 3.48 & .078 & .162 & 10.47 & $.005^{* * *}$ & .368 & .00 & .985 & .000 \\
\hline $550-600$ & .23 & .637 & .013 & 8.70 & $.009^{* * *}$ & .326 & .32 & .579 & .017 \\
\hline $600-650$ & 2.70 & .118 & .131 & 6.63 & $.019^{*}$ & 269 & 6.41 & $.021^{*}$ & .262 \\
\hline $650-700$ & .374 & .548 & .020 & 6.71 & $.018^{*}$ & .272 & 6.07 & $.024^{*}$ & .252 \\
\hline
\end{tabular}

${ }^{*} p<.05 ;{ }^{* *} p<.01,{ }^{* *}=$ significant results after correction for multiple comparisons

count, only the Pz effect remained significant. As depicted in Figure 5 , the CNV in self condition was slightly more negative compared to denied condition.

For the three time windows from -300 to $0 \mathrm{~ms}$, emotional content interacted significantly with electrode $(-300$ to $-200 \mathrm{~ms}: F[5,90]=$ $3.013, p=.05 ;-200$ to $-100 \mathrm{~ms}: F(5,90)=4.478, p=.013 ;-100$ to -0 ms: $F(5,90)=4.599, p=.011)$. Post-hoc single comparisons of neutral versus negative emotional content at all six electrodes for these three time windows revealed no significant effects, all $t s<1.857$, ps $>.08$.

\section{FRN}

Data from two participants was discarded because they did not exhibit enough artifact-free trials in one or more conditions. Data from the remaining 17 participants are included in the reported results of repeated-measures ANOVAs.

Amplitudes. While there were no significant main effects of choice, $F(1,16)=.05, p=.835, \mathrm{n}_{\mathrm{p}}{ }^{2}=.003$, or emotional content, $F(1$, 16) $<.01, p=.988, \mathrm{n}_{\mathrm{p}}{ }^{2}<.001$, there was a significant main effect of feedback type on FRN amplitudes, $F(1,16)=26.71, p<.001, \mathrm{n}_{\mathrm{p}}{ }^{2}=$ .625 with more negative amplitudes for negative $(M=-9.66, S E=$ 1.10) compared to positive feedback $(M=-6.43)$. Interactions between factors were not significant, all $p s>.198$.

Latencies. No significant main effect of choice, $F(1,16)=2.05$, $p=.172, \mathrm{n}_{\mathrm{p}}{ }^{2}=.113$, emotional content, $F(1,16)=.37, p=.550, \mathrm{n}_{\mathrm{p}}{ }^{2}$ $=.023$, or feedback, $F(1,16)=.04, p=.852, \mathrm{n}_{\mathrm{p}}{ }^{2}=.002$, was evident on FRN latencies. However, there was a significant choice $\times$ emotional content interaction, $F(1,16)=6.33, p=.023, \mathrm{n}_{\mathrm{p}}{ }^{2}=.284$, and a strong trend towards a choice $\times$ emotional content $\times$ feedback interaction, $F(1,16)=4.44, p=.051, \mathrm{n}_{\mathrm{p}}{ }^{2}=.217$. Follow-up t tests on the significant choice $\times$ emotional content interaction revealed that while there was no significant difference on FRN latencies between neutral $(M=76.47, S E=4.50)$ and negative trials $(M=$ 83.12, $S E=7.35)$ in the self condition, $t(16)=-1.306, p=.210, d$ $=-0,264$, this difference was significant for the denied condition, $t(16)=2.365, p=.031, d=.454$, with larger latencies for neutral trials $(M=88.65, S E=5.53)$ compared to negative trials $(M=77.88$, $S E=5.97)$. Exploratory results on the almost significant three-way interaction of choice $\times$ emotional content $\times$ feedback showed that this pattern resulted from negative feedback trials such that significant differences between neutral and negative trials were not found for self choices $t(16)=-1.815, p=.088, d=-.555$, but were found for denied choices $t(16)=3.201, p=.006, d=.720$ (see Figure 5).
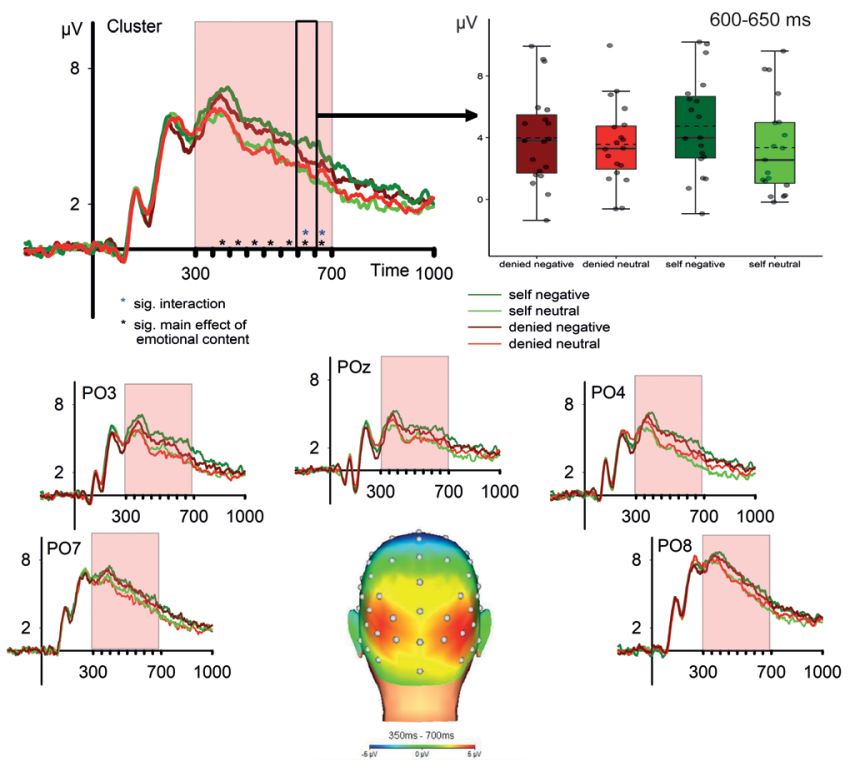

\section{FIGURE 4.}

Late positive potential (LPP) results for posterior cluster and single electrodes including analyzed time window of 300-700 ms (red). * indicate significant effects with $\mathrm{p}<.05$. Box plots depict interaction effect for time window of 600-650 ms, representing median (solid line) and mean (dashed line) amplitudes in $\mu \mathrm{V}$. Error bars define outliers with values greater than 1.5 interquartile range of median. - Topographic map depicts LPP topography including significant interaction effects for time window 350-700 ms. 


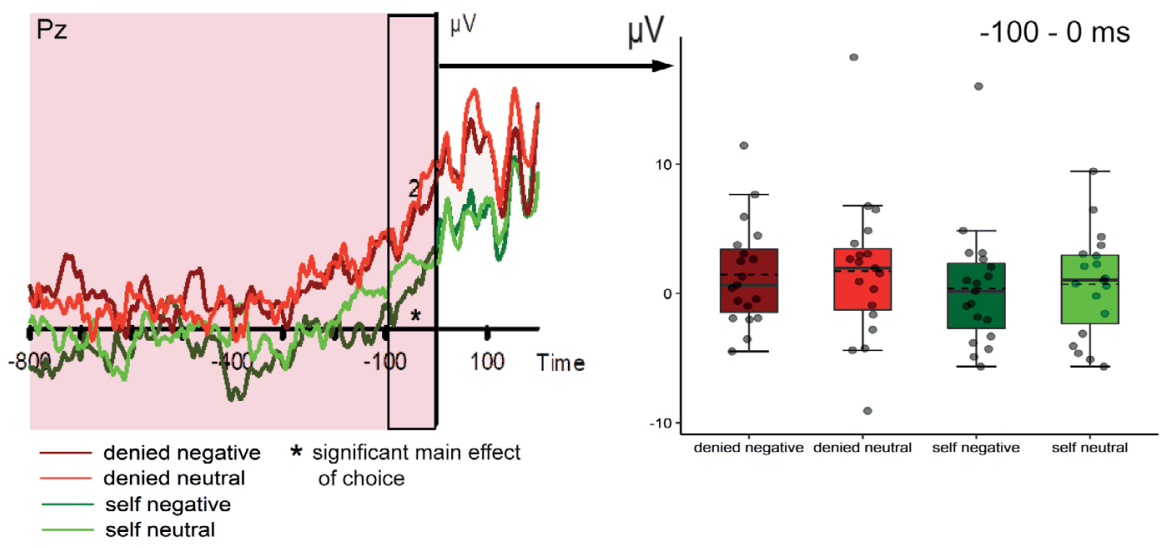

\section{FIGURE 5.}

Pre-response contingent negative variation (CNV) results at electrode Pz, showing greater CNV for self compared to denied trials in the time window from -100 to 0 ms (red background). Box plot depicts median (solid line), mean (dashed line), error bars define outliers - with values greater than 1.5 inter quartile range of median)

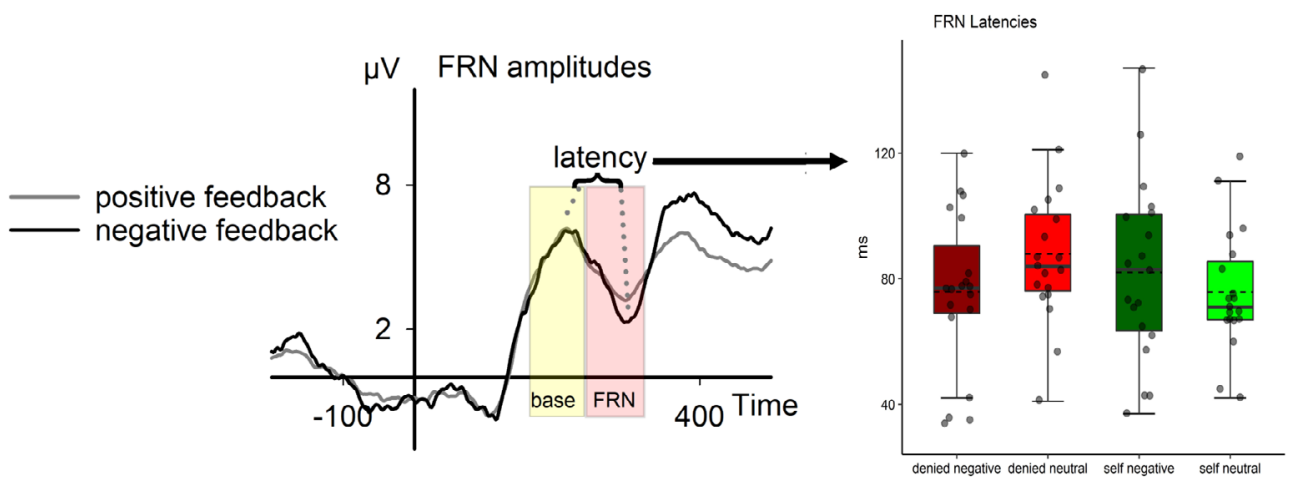

\section{FIGURE 6.}

Left: The feedback valence effect. Yellow and red illustrate how feedback-related negativity (FRN) latencies were measured from base (yellow) to peak (red). The FRN latencies, separated for choice and emotional content, are shown for trials with negative feedback in the boxplot in the right part. Box plot depicts median (solid line) and mean (dashed line), error bars define outliers with values greater than 1.5 inter quartile range of median.

However, for positive feedback, no significant differences between neutral and negative trials were found for either self, $t(16)=.072, p$ $=.944, d=.016$, or denied trials, $t(16)=.137, p=.893, d=.034$. All other interactions were not significant $(p s>.768)$.

\section{DISCUSSION}

In the present study, we investigated the dynamic interactions of motivational and affective signals during task engagement in a temporal production task. Based on the assumption that self-determined choices modulate task performance via altered cognitive and emotional processing, we manipulated choice by either approving or denying participants' choices of preferred stimulus categories to be displayed during a temporal production task with neutral and negative pictures. We tested the effects of motivational state and emotional content on ERP components over the time course of task preparation (CNV), task engagement (LPP) and feedback processing (FRN).

Behavioral results indicated that task performance was affected by both factors in an interactive pattern - participants' temporal productions were closer to the target time in the negative compared to the neutral condition under self-determined choice but not under denied choice.

EEG data provide preliminary evidence for dynamic interactions between motivational and emotional processes over time. First, task preparation as measured in the pre-stimulus CNV was increased in the 
pre-stimulus interval for self-determined choices compared to denied choices. Second, in the time window after emotional picture onset, LPP amplitudes were greater for negative stimuli than neutral stimuli. Interestingly, the data indicate that this effect may persist longer in the self than in the denied condition, as indicated by interactive effects in the later time windows of the LPP. However, these interaction effects did not withstand correction for multiple comparisons and therefore should be considered with caution. An enhanced pre-response $\mathrm{CNV}$ for self-determined responses was observed $100 \mathrm{~ms}$ before the response compared with denied choices. Finally, feedback-related signals also depended on emotional content and on choice, as reflected in latency differences. These findings indicate that motivational and emotional processes might be integrated over time to modulate task engagement during cognitive task processing in addition to outcomerelated processing.

\section{Choice and Overt Task Performance}

Participants generally overestimated the target time, but more so in self-determined trials for neutral compared to negative pictures. Once the button was pressed for temporal production, picture content disappeared from the screen. Faster responses to negative stimuli seem in line with predictions of overall facilitated processing of negative and arousing compared to neutral stimuli (Contreras et al., 2013; Huang \& Luo, 2006; Kousta et al., 2009). As is evident in the interaction, motivational processing and, in particular, self-determination are crucial for this effect such that this processing bias is only visible in the self condition. These findings are also in line with the expectation that choice and emotional content influence attentional processes such that more motivation and more stimulus emotionality attract more attentional resources (Pessoa, 2009) which here becomes evident in shorter subjective trial durations and relatively faster time productions for negative stimuli in the self condition (Matthews \& Meck, 2016). Observed differences between conditions were in the range between $\sim 30$ and $\sim 60 \mathrm{~ms}$, which is in line with previous reports in emotion and motivation research (cf. Huskey et al., 2018; Mori et al., 2018). In the computed statistical model, these condition effects explained about 3\% of variance in the absolute differences from the time production interval, with some amounts of individual variance remaining unexplained by the conditions. Still, such results are comparable to variances explained in emotional stimulus processing (cf. 5.5\% in Larsen et al., 2008). Note that we did not provide participants with explicit instructions regarding internal strategies for solving the time production task. Therefore, whether or not different strategies like chronometric counting, visualizing a clock, tapping, or others (Brown \& Merchant, 2007) might affect the present modulations cannot be inferred. However, we did not find any effects of choice or emotion on absolute deviation times. Other researchers who studied the effects of choice on task performance reported increased performance when self-determined choices could be made in a Stroop task (Legault \& Inzlicht, 2013) as well as in a stopwatch task (Murayama et al., 2013). An explanation for the present null finding regarding choice effects on absolute deviations might be found in our study design. First, trials were rather long in time, which might have led to a "wash-out" of the modulations present over the time course of the trial. Second, after choosing the picture category, participants still did not know which emotional content they were going to encounter. This might have induced a state of uncertainty interacting with the strength of motivational modulations of task engagement. It seems likely that this uncertainty that was not under the control of participants diminished the effects of self-determination to some extent, thus reducing their propagation to the behavioral level. Reducing this uncertainty while maintaining the freedom to choose might be addressed in future studies.

\section{Choice in Task and Response Preparation (CNV)}

Prestimulus CNV amplitudes were measured in response to encountering feedback regarding whether the category choice was accepted (self trials) or rejected (denied trials). Analyses of the ERPs during this time window showed a more negative going curve for self compared to denied trials. A larger $\mathrm{CNV}$ has often been taken to indicate alertness and motor preparation for the response to an upcoming stimulus (Caldara et al., 2004; Vuillier et al., 2015). Having chosen a stimulus category based on one's individual preferences and being confirmed in that choice can be assumed to elicit a state of intrinsic motivation and associated positive affect (Leotti et al., 2010; Patall et al., 2008). In contrast, the rejection of that choice can be assumed to counteract this motivational state and induce negative affect. The finding of a CNV modulation based on this motivational manipulation indicates that motor-cognitive task preparation processes are susceptible to transient motivational states, which might then propagate to subsequent task engagement.

While an increased CNV related to self-determined choice seems plausible, the alternative interpretation that notification of the rejection of one's choice might trigger further processes that result in a diminished CNV amplitude should also be considered. The restriction of choice and personal freedom has been investigated in terms of psychological reactance (Brehm, 1966), such that denied options appear more attractive in retrospect when they are no longer available. Therefore, being deprived of the denied category likely preoccupies participants differently, leading to reduced preparation for the upcoming trial that is reflected in diminished CNV amplitudes (which indicate less preparation in such denied trials). Reduced preparatory options have also been associated to diminished CNV amplitudes in a task-switching paradigm by Forstmann et al. (2007), who manipulated the number of task options participants were able to choose from and their influence on ERPs. In their design, less choice allowed for better task preparation and was associated with larger CNV amplitudes. In our study design, preparatory processes did not differ depending on choice. In this case, more motivation in self-choice trials or diminished motivation in denied-choice trials appeared to influence pre-stimulus CNV amplitudes.

In addition, we analyzed the $\mathrm{CNV}$ in the response preparation interval and found a significant effect for self compared with denied choices shortly before the response in the -100 to $0 \mathrm{~ms}$ time window. As for the pre-stimulus $\mathrm{CNV}$ the pre-response $\mathrm{CNV}$ was enhanced for 
self responses. However, this effect was only present at the Pz electrode over the parietal cortex. Hence, the pre-response CNV showed a rather unexpected scalp distribution as response preparation processes, especially in time estimation tasks, are usually related to frontocentral brain areas (van Rijn et al., 2011). Therefore, it remains open whether the motivational effect in self-determined choices directly affects motor preparation or has to be ascribed to broader processes of executive attention.

In sum, both CNV results suggest that preparation for an upcoming trial and for the response depend on the perceived degree of autonomy with which participants can or cannot influence a trial via the choice of a category.

\section{Choice, Emotion and Outcome Processing (FRN)}

In response to emotional picture presentation, we found larger positive amplitudes for negative content compared to neutral content from 350 to $700 \mathrm{~ms}$, thereby corroborating previous findings on effects of valence on LPP amplitudes (Cuthbert et al., 2000; Dolcos \& Cabeza, 2002; Keil et al., 2002). Emotional modulations of this positivity have been related to differences in sustained attention and evaluative processing, being larger for more salient or relevant stimuli. The evolutionary-based higher relevance of negative stimuli displayed in the ERP amplitudes found here has been well-established by a number of researchers (Carretie et al. , 2001; Ito et al., 1998; Smith et al., 2003) and, therefore, integrates well into the large body of literature of taskirrelevant processing of emotional content.

Choice affected LPP amplitudes relatively late during the trial, not starting until $600 \mathrm{~ms}$ after picture appearance. Also, choice effects were only weak for the LPP, notwithstanding correction for multiple comparisons. This suggests that in the initial phase of the trial, processing of the pictures occurred in a bottom-up manner, purely driven by the picture content without any higher-level influence of motivation. This is somewhat surprising, since one might expect participants to allocate more attention to pictures of a category they chose and therefore wanted to see, compared to pictures of categories of denied-choice trials they did not pick throughout.

One explanation for the missing early effect of choice on LPP amplitudes might be that participants noticed relatively quickly that an accepted choice could still turn out negatively in terms of the shown content. For example, a pet-friendly individual might choose the animal category frequently. However, seeing pictures of injured animals can be assumed to affect the positive motivational state elicited by choice. As $50 \%$ of the pictures were negative in content, participants might have regulated their picture processing in advance such that positive motivational states would not conflict with these contents.

The data indicate that choice may have influenced amplitudes in the later time windows of the LPP when more conscious, evaluative processing occurred (see Olofsson et al., 2008, for a review of the time course of emotional picture processing). In these later time windows, an effect of emotional content was only evident for self choices with larger amplitudes in response to negative compared to neutral pictures.
As shown in Figure 4, self trials with negative emotional content stood out against all other trial types, thereby mirroring results regarding the accuracy of absolute temporal production times. As outlined above, this seems to indicate that in a state of high intrinsic motivation, emotional content may be processed more intensely.

The theory of affective attentional modulations being susceptible to motivational states during cognitive task performance is supported by Pessoa (2009), who focused on interaction effects that influenced performance in cognitive tasks. Relating his concept to the current results suggests that the sustained high LPP amplitudes for negative pictures in the self condition are the result of the combination of evolutionarily more meaningful stimuli (negative as compared to neutral pictures) and a motivational state (self-determined as compared to rejected) that together led to a longer lasting allocation of attentional resources. A surplus of attention towards negative as compared to neutral pictures in the motivational condition thus explains LPP findings and the matching interaction found in results on absolute time productions where responses in self trials were most accurate after negative pictures. However, improved performance for trials of specific conditions were not evident in results on deviation times.

Support for the findings comes from research on temporal cognition, where Matthews and Meck (2016) elaborate that subjective duration of a stimulus is positively related to the strength of its perceptual representation. Applying this concept to our data suggests that for self choices, the evolutionarily meaningful negative pictures might be associated with a stronger perceptual representation compared to neutral pictures, as reflected in LPP amplitudes. Additionally, the stronger perceptual representation likely resulted in longer perceived duration of the negative images and, in turn, in shorter response times.

An alternative explanation for the results can be deducted from Rothermund et al. (2008), who studied biases for affective stimuli that are incongruent to the current motivational state. The authors describe that this incongruency serves the purpose of balancing out emotional states. Automatically allocating attention towards positive stimuli when in a bad motivational state can lead to a readjustment towards a more neutral mood. Vice versa, focusing on negative stimuli can balance out a very positive emotional state. The sustained amplitudes in response to negative pictures in self-determined trials can, in that sense, be interpreted as persisting attentional effects elicited by the incongruency of motivational state and affective picture content.

While the present findings indicate interactions between emotional and motivational effects, it is important to point out that our results cannot be univocally attributed to the influence of the negative emotional content per se. As we did not include comparable positive images, it is not clear whether more pronounced valence or higher arousal for negative compared to neutral pictures caused the robust LPP modulation. Therefore, it cannot be disentangled whether in this case, the LPP was sensitive to emotional content, arousal or both, all of which are partly supported by the aforementioned literature (cf. Olofsson et al., 2008).

Additionally, the trial categories were limited in number, since only eight were available for all 224 trials, meaning that the choice options 
might have appeared restrained after a while. Throughout the course of the task, participants might not have constantly kept up the sense of self-determination on accepted trials but rather might have developed a sense for the boundaries that the choices were confined in.

\section{Choice, Emotion and Attention (LPP)}

The FRN amplitudes were more negative in response to negative feedback compared to trials with positive feedback, corroborating the majority of research on the FRN as indicator of feedback valence (Hajcak et al., 2006; Holroyd et al., 2003). Following this line of research, the absent FRN amplitude modulation depending on choice and emotional content suggests that besides modulation of valence, the feedback participants got for different trial categories was evaluated similarly. However, we did find an interaction of choice and emotional content on the latency of the FRN. Investigating this pattern, it became evident that for denied choices with neutral picture content, the onset of the FRN was later than for denied choices with negative picture content and self-choice trials with either neutral or negative content. Research regarding FRN latencies is scarce, leaving us with only assumptions about the meaning of these findings. Possibly, feedback was equally meaningful for self and denied trials, as reflected in the comparable height of the amplitudes. Still, an increase in motivation on self trials might have speeded up feedback processing to such a degree that other typical influences like increased attention to negative stimuli might not be able to additionally speed up processing beyond the effect of motivation. Overall, participants were likely less motivated to process feedback for denied trials. However, negative pictures draw more emotional attention than neutral ones (Pourtois et al., 2013) and thereby decrease the latency of respective ERP components (Valt \& Sturmer, 2017). Even though motivation to receive feedback for denied choices was likely diminished, resulting in increased latencies relative to self trials, emotional attention might have again decreased FRN latencies for negative scenes in denied-choice trials. Therefore, the influence on FRN latency might be explained in terms of overall increased motivation in self-choice trials resulting in accelerated feedback processing, but not further decreased by emotional picture content, and emotional attention increasing processing speed for feedback after negative scenes in the overall less motivating denied trials.

\section{Intrinsic versus extrinsic motivation}

In their theory of self-determination, Ryan and Deci (2000) distinguish between intrinsic motivation, that is, something that is rewarding in itself, and extrinsic motivation, that is, a reward is to be expected for doing something that by itself is not necessarily rewarding. This idea is taken up by Ly et al. (2019), who propose a model of perceived control that consists of choice, action-outcome contingencies, and reward rate. Choice options are thought of as being rewarding and appetitive by themselves, not only in cases where they increase outcome value (Brown et al., 2003). This intrinsic motivation for choice options has been studied extensively by Leotti and Delgado (2011, 2014), who identified corticostriatal pathways involved in the anticipation of choice, reflecting its inherently rewarding aspect (Haber \& Knutson,
2010). Even though inherent reward in choice can be assumed, specifics of study designs influence the degree of self-determination that is conveyed to participants (Patall et al., 2008). At present, little is known about the role of different types of self-determined choices for intrinsic motivation. In line with previous studies (Leotti \& Delgado, 2011; Murayama et al. 2013), participants' choices in the current study were not associated with the performance of a completely different task, but changed only a specific task component (in the case of our study, the presented stimulus picture). While more freedom in choice might enhance modulatory effects on cognitive processing, we find it important to disentangle effects of different types of choice further in the future.

Furthermore, two aspects are highlighted which appear important to understand the uniqueness of the current results and their relation to the larger body of research on motivation and reward. In the studies which established the reward of choice, Leotti and Delgado (2011, 2014) compared trials with a choice option to trials where no choices could be made (preselection by a computer). Contrary to this procedure, we had participants choose a picture category on every trial, but half of them were rejected. We did so as we expected to maximize motivational differences between the choice condition and the control condition. However, having a choice rejected likely feels different from having nothing to choose from in the first place. In that sense, our study design differs from that of Leotti and Delgado (2011, 2014). Future studies might address the significance of the choice of a control group for assessing intrinsic motivational effects by directly comparing different control conditions. The type of control group has also been identified as a moderator of choice effects in a meta-analysis (Patall et al., 2008). Additionally, Ryan and Deci (2000) summarize that intrinsic motivation can be undermined by, for example, extrinsic reward, since it might appear as if one's behavior is controlled and not fully self-determined. In the current study, participants' choices were, as mentioned before, rejected in half of the trials, which might have felt like a second instance was in control, not just the participants themselves. In this sense, the intrinsic motivation that supposedly came with choice and a feeling of perceived control were likely confounded to some extent.

\section{Limitations}

The present study provides first insights into the dynamic interplay of emotional and motivational modulations of task engagement in a temporal production task. The rather small sample size clearly limits the degree to which the results can be generalized at this point. In particular, the interaction effect in the time-windowed analysis of the LPP did not withstand a correction for multiple comparisons and therefore must be considered as preliminary. Also, future studies should consider alternative analysis approaches, such as explorative ERP analyses using cluster-based permutation methods or a mass univariate approach (Groppe et al., 2011) which allows parallel computations of all time windows and electrodes in an explorative manner applying Benjamini and Hochberg's (1995) corrections to control false discovery rate in multiple comparisons. Finally, individual differences analy- 
ses regarding trait motivational factors together with subjective reports regarding task motivation should be considered in future studies with larger samples to expand the understanding of individual differences in emotion-motivation interactions.

\section{Conclusions}

In the present study, we provide preliminary evidence for the assumption that motivational and emotional processes interact over time to modulate task engagement during cognitive task processing in a temporal production task. Even though some specifics of our design might have diminished effects of intrinsic reward related to self-determined choice, these effects were still evident on several outcome measures. Preparation for the upcoming task was more pronounced for selfcompared to denied-choice trials, as was manifest in differential amplitudes of the CNV. Choice also interacted with emotional content of the shown pictures in two investigated time intervals-during the LPP after picture onset and during temporal production feedback processing. In order to disentangle the effects of choice and reward and also their interaction with emotional content, future studies are needed using an adjusted study design. Including a no-choice option in addition to self- and denied-choice would provide the opportunity to compare choice trials to a more neutral condition. Effects of denied choices could be compared to the no-choice option as well, thereby revealing the degree to which denied choices were perceived as external control over one's choice. Including a category of positive pictures in addition to neutral and negative pictures would also be beneficial. With this third picture category, it would be possible to verify whether picture valence or arousal were driving the effects during the time window of the LPP and on FRN latencies.

\section{ACKNOWLEDGEMENTS}

This work was supported by the Stiftung zur Förderung der universitären Psychoanalyse.

We thank Sofia Kontaxi for assistance in data processing.

\section{REFERENCES}

Bandura, A., \& Wood, R. (1989). Effect of perceived controllability and performance standards on self-regulation of complex decision making. Journal of Personality and Social Psychology, 56(5), 805-814. Benjamini, Y., \& Hochberg, Y. (1995). Controlling the false discovery rate: a practical and powerful approach to multiple testing. Journal of the Royal Statistical Society: Series B (Methodological), 57(1), 289-300. doi:10.1111/j.2517-6161.1995.tb02031.x المالمسلسال

Bown, N. J., Read, D., \& Summers, B. (2003). The lure of choice. Journal of Behavioral Decision Making, 16(4), 297-308. doi:10.1002/ bdm.447 الس السلس

Brown, S. W., \& Merchant, S. M. (2007). Processing resources in timing and sequencing tasks. Perception \& Psychophysics, 69(3), 439-449. doi:10.3758/bf03193764 سلس

Brehm, J. W. (1966). A theory of psychological reactance. Academic Press. Cacioppo, J. T., Petty, R. E., Feinstein, J. A., Blair, W., \& Jarvis, G. (1996).
Dispositional differences in cognitive motivation: The life and times of individuals varying in need for cognition. Psychological Bulletin,

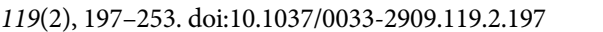

Caldara, R., Deiber, M. P., Andrey, C., Michel, C. M., Thut, G., \& Hauert, C. A. (2004). Actual and mental motor preparation and execution: A spatiotemporal ERP study. Experimental Brain Research, 159(3), 389-399. doi:10.1007/s00221-004-2101-0 السلسلس السلس

Carretie, L., Mercado, F., Tapia, M., \& Hinojosa, J. A. (2001). Emotion, attention and the 'negativity bias', studied through event-related potentials. International Journal of Psychophysiology, 41(1), 75-85. doi:10.1016/s0167-8760(00)00195-1 البلسلسلس

Cerasoli, C. P., Nicklin, J. M., \& Ford, M. T. (2014). Intrinsic motivation and extrinsic incentives jointly predict performance: A 40-year meta-analysis. Psychological Bulletin, 140(4), 980-1008. doi:10.1037/

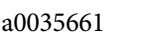

Contreras, D., Megias, A., Maldonado, A., Candido, A., \& Catena, A. (2013). Facilitation and interference of behavioral responses by task-irrelevant affect-laden stimuli. Motivation and Emotion, 37(3), 496-507. doi:10.1007/s11031-012-9327-0

Cordova, D. I., \& Lepper, M. R. (1996). Intrinsic motivation and the process of learning: Beneficial effects of contextualization, personalization, and choice. Journal of Educational Psychology, 88(4), 715-730. doi:10.1037/0022-0663.88.4.715 كالس

Cosme, D., Mobasser, A., Zeithamova, D., Berkman, E. T., \& Pfeifer, J. H. (2018). Choosing to regulate: Does choice enhance craving regulation? Social Cognitive and Affective Neuroscience, 13(3), 300-309. doi:10.1093/scan/nsy010 المسلس

Csikszentmihalyi, M., Abuhamdeh, S., \& Nakamura, J. (2005). Flow. In A. J. Elliot \& C. S. Dweck (Eds.), Handbook of competence and motivation (pp. 598-608). Guilford Publications.

Cuthbert, B. N., Schupp, H. T., Bradley, M. M., Birbaumer, N., \& Lang, P. J. (2000). Brain potentials in affective picture processing: Covariation with autonomic arousal and affective report. Biological Psychology, 52(2), 95-111. doi:10.1016/S0301-0511(99)00044-7 السلسلس

Deci, E. L., Connell, J. P., \& Ryan, R. M. (1989). Self-determination in a work organization. Journal of Applied Psychology, 74(4), 580-590.

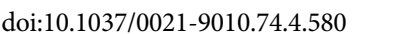

Dehaene, S., Posner, M. I., \& Tucker, D. M. (1994). Localization of a neural system for error detection and compensation. Psychological

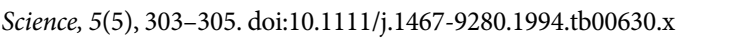

Dolcos, F., \& Cabeza, R. (2002). Event-related potentials of emotional memory: Encoding pleasant, unpleasant, and neutral pictures. Cognitive Affective and Behavioral Neuroscience, 2(3), 252-263.

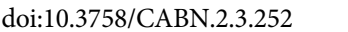

Dreisbach, G., \& Goschke, T. (2004). How positive affect modulates cognitive control: reduced perseveration at the cost of increased distractability. Journal of Experimental Psychology: Learning, Memory, and Cognition, 30(2), 343-353. doi:10.1037/0278-7393.30.2.343 الملسلسلة

Droit-Volet, S., Brunot, S., \& Niedenthal, P. (2004). BRIEF REPORT Perception of the duration of emotional events. Cognition and Emotion, 18(6), 849-858. doi:10.1080/02699930341000194 المالسلس Droit-Volet, S., \& Meck, W. H. (2007). How emotions colour our 
perception of time. Trends in Cognitive Sciences, 11(12), 504-513. doi:10.1016/j.tics.2007.09.008 الس الس الس الس

Droit-Volet, S., \& Gil, S. (2009). The time-emotion paradox. Philosophical Transactions of the Royal Society B: Biological Sciences, 364(1525), 1943-1953. doi:10.1098/rstb.2009.0013 المالسلس

Engelmann, J. B., \& Pessoa, L. (2007). Motivation sharpens exogenous spatial attention. Emotion, 7(3), 668-674. doi:10.1037/15283542.7.3.668 سلس

Engelmann, J. B., Damaraju, E., Padmala, S., \& Pessoa, L. (2009). Combined effects of attention and motivation on visual task performance: Transient and sustained motivational effects. Frontiers in Human Neuroscience, 3:4. doi:10.3389/neuro.09.004.2009 البلسلس

Forstmann, B. U., Brass, M., Koch, I., \& von Cramon, D. Y. (2006). Voluntary selection of task sets revealed by functional magnetic resonance imaging. Journal of Cognitive Neuroscience, 18(3), 388-398. doi:10.1162/089892906775990589 سلس

Forstmann, B. U., Ridderinkhof, K. R., Kaiser, J., \& Bledowski, C. (2007). At your own peril: an ERP study of voluntary task set selection processes in the medial frontal cortex. Cognitive, Affective, \& Behavioral Neuroscience, 7(4), 286-296. doi:10.3758/CABN.7.4.286 البلسلس

Groppe, D. M., Urbach, T. P., \& Kutas, M. (2011). Mass univariate analysis of event-related brain potentials/fields II: Simulation studies. Psychophysiology, 48(12), 1726-1737. doi:10.1111/j.1469-

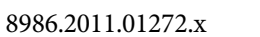

Haber, S. N., \& Knutson, B. (2010). The reward circuit: Linking primate anatomy and human imaging. Neuropsychopharmacology. American College of Neuropsychopharmacology, 35(1), 4-26. doi:10.1038/npp.2009.129 سلسلسلس

Haggard, P. (2008). Human volition: Towards a neuroscience of will. Nature Reviews Neuroscience, 9(12), 934-946. doi:10.1038/nrn2497 الس السلسل

Hajcak, G., Moser, J. S., Holroyd, C. B., \& Simons, R. F. (2006). The feedback-related negativity reflects the binary evaluation of good versus bad outcomes. Biological Psychology, 71(2), 148-154. doi:10.1016/j.biopsycho.2005.04.001

Holroyd, C. B., \& Coles, M. G. (2002). The neural basis of human error processing: reinforcement learning, dopamine, and the error-related negativity. Psychological Review, 109(4), 679-709. doi:10.1037/0033295X.109.4.679

Holroyd, C. B., Nieuwenhuis, S., Yeung, N., \& Cohen, J. D. (2003). Errors in reward prediction are reflected in the event-related brain potential. Neuroreport, 14(18), 2481-2484. doi:10.1097/00001756-

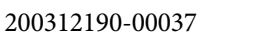

Huang, Y. X., \& Luo, Y. J. (2006). Temporal course of emotional negativity bias: An ERP study. Neuroscience Letters, 398(1-2), 91-96. doi:10.1016/j.neulet.2005.12.074 الس السلس

Huebner, R., \& Schlosser, J. (2010). Monetary reward increases attentional effort in the flanker task. Psychonomic Bulletin \& Review, 17(6), 821-826. doi:10.3758/PBR.17.6.821 1لس

Huskey, R., Craighead, B., Miller, M. B., \& Weber, R. (2018). Does intrinsic reward motivate cognitive control? A naturalistic-fMRI study based on the synchronization theory of flow. Cognitive, Affective, \& Behav Neuroscience, 18(5), 902-924. doi:10.3758/s13415-018-0612-6 المالسلس
Ito, T. A., Larsen, J. T., Smith, N. K., \& Cacioppo, J. T. (1998). Negative information weighs more heavily on the brain: The negativity bias in evaluative categorizations. Journal of Personality and Social Psychology, 75(4), 887-900. doi:10.1037/0022-3514.75.4.887 الس الس الس

Karayanidis, F., Coltheart, M., Michie, P. T., \& Murphy, K. (2003). Electrophysiological correlates of anticipatory and poststimulus components of task switching. Psychophysiology, 40(3), 329-348. doi:10.1111/1469-8986.00037 سلس السلس

Keil, A., Bradley, M. M., Hauk, O., Rockstroh, B., Elbert, T., \& Lang, P. J. (2002). Large-scale neural correlates of affective picture-processing.

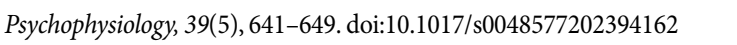
Kousta, S.-T., Vinson, D. P., \& Vigliocco, G. (2009). Emotion words, regardless of polarity, have a processing advantage over neutral words.

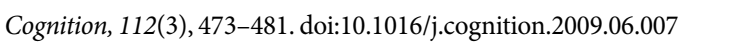

Kropp, P., Kiewitt, A., Gobel, H., Vetter, P., \& Gerber, W.-D. (2000). Reliability and stability of contingent negative variation. Applied Psychophysiology and Biofeedback, 25(1), 33-41. doi:10.1023/a:1009533405695 الس الس

Kuhl, J. (1990). Fragebogen zur Erfassung der Handlungskontrolle: HAKEMP-90. Universität Osnarbrück.

Lang, P. J., Greenwald, M. K., Bradley, M. M., \& Hamm, A. O. (1993). Looking at pictures: Affective, facial, visceral, and behavioral reactions. Psychophysiology, 30(3), 261-273. doi:10.1111/j.1469-8986.1993.tb03352.x الس الس الس

Larsen, R. J., Mercer, K. A., Balota, D. A., \& Strube, M. J. (2008). Not all negative words slow down lexical decision and naming speed: Importance of word arousal. Emotion, 8(4), 445-452. doi:10.1037/1528-3542.8.4.445 (لسلس

Legault, L., \& Inzlicht, M. (2013). Self-determination, self-regulation, and the brain: Autonomy improves performance by enhancing neuroaffective responsiveness to self-regulation failure. Journal of Personality and Social Psychology, 105(1), 123-138. doi:10.1037/ a0030426 السلسلس

Leotti, L. A., \& Delgado, M. R. (2011). The inherent reward of choice. Psychological Science, 22(10), 1310-1318. doi:10.1177/0956797611417005 الس السلسل

Leotti, L. A., \& Delgado, M. R. (2014). The value of exercising control over monetary gains and losses. Psychological Science, 25(2), 596-604. doi:10.1177/0956797613514589 سلس

Leotti, L. A., Iyengar, S. S., \& Ochsner, K. N. (2010). Born to choose: the origins and value of the need for control. Trends in Cognitive

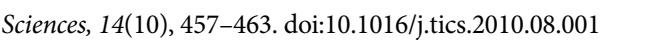

Ly, V., Wang, K. S., Bhanji, J., \& Delgado, M. R. (2019). A reward-based framework of perceived control. Frontiers in Neuroscience, 13:65. doi:10.3389/fnins.2019.00065 سلس

Maier, S. F., \& Watkins, L. R. (2010). Role of the medial prefrontal cortex in coping and resilience. Brain Research, 1355, 52-60. doi:10.1016/j. brainres.2010.08.039 |ل|

Marchewka, A., Zurawski, L., Jednorog, K., \& Grabowska, A. (2014). The Nencki Affective Picture System (NAPS): introduction to a novel, standardized, wide-range, high-quality, realistic picture database. Behavior Research Methods, 46(2), 596-610. doi:10.3758/ 


\section{s13428-013-0379-1}

Matthews, W. J., \& Meck, W.H. (2016). Temporal cognition: Connecting subjective time to perception. Attention, and Memory. Psychological Bulletin, 142(8), 865-907. doi:10.1037/bul0000045 每

Mori, A., Okamoto, Y., Okada, G., Takagaki, K., Takamura, M., Jinnin, R., .. Y Yamawaki, S. (2018). Effects of behavioural activation on the neural circuit related to intrinsic motivation. BJPsych Open, 4(5), 317-323. doi:10.1192/bjo.2018.40 الم

Murayama, K., Matsumoto, M., Izuma, K., Sugiura, A., Ryan, R. M., Deci, E. L., \& Matsumoto, K. (2013). How self-determined choice facilitates performance: A key role of the ventromedial prefrontal cortex. Cerebral Cortex, 25(5), 1241-1251. doi:10.1093/cercor/ bht317 |لس

Ng, J. Y., Ntoumanis, N., Thogersen-Ntoumani, C., Deci, E. L., Ryan, R. M., Duda, J. L., \& Williams, G. C. (2012). Self-determination theory applied to health contexts: A meta-analysis. Perspectives on Psychological Science, 7(4), 325-340. doi:10.1177/1745691612447309 المالسلسلس

Olofsson, J. K., Nordin, S., Sequeira, H., \& Polich, J. (2008). Affective picture processing: an integrative review of ERP findings. Biological Psychology, 77(3), 247-265. doi:10.1016/j.biopsycho.2007.11.006 الملكلـلس

Orr, J. M., \& Banich, M. T. (2014). The neural mechanisms underlying internally and externally guided task selection. Neuroimage, 84, 191-205. doi:10.1016/j.neuroimage.2013.08.047 سلس

Passingham, R. E., Bengtsson, S. L., \& Lau, H. C. (2010). Medial frontal cortex: From self-generated action to reflection on one's own performance. Trends in Cognitive Sciences, 14(1), 16-21. doi:10.1016/j. tics.2009.11.001 سلس

Paschke, L. M., Walter, H., Steimke, R., Ludwig, V. U., Gaschler, R., Schubert, T., \& Stelzel, C. (2015). Motivation by potential gains and losses affects control processes via different mechanisms in the attentional network. Neuroimage, 111, 549-561. doi:10.1016/j. neuroimage.2015.02.047 एلس

Patall, E. A., Cooper, H., \& Robinson, J. C. (2008). The effects of choice on intrinsic motivation and related outcomes: A meta-analysis of research findings. Psychological Bulletin, 134(2), 270-300. doi:10.1037/0033-2909.134.2.270 المالمسلس

Pessoa, L. (2009). How do emotion and motivation direct executive control? Trends in Cognitive Sciences, 13(4), 160-166. doi:10.1016/j. tics.2009.01.006 سلس

Polich, J. (2007). Updating P300: An integrative theory of P3a and P3b. Clinical Neurophysiology, 118(10), 2128-2148. doi:10.1016/j. clinph.2007.04.019 السلسلس

Pourtois, G., Schettino, A., \& Vuilleumier, P. (2013). Brain mechanisms for emotional influences on perception and attention: What is magic and what is not. Biological Psychology, 92(3), 492-512. doi:10.1016/j. biopsycho.2012.02.007 崖

Rothermund, K., Gast, A., \& Wentura, D. (2011). Incongruency effects in affective processing: Automatic motivational counter-regulation or mismatch-induced salience? Cognition and Emotion, 25(3), 413-425. doi:10.1080/02699931.2010.537075 السلسلسلس

Rothermund, K., Voss, A., \& Wentura, D. (2008). Counter-regulation in affective attentional biases: A basic mechanism that warrants flexibility in emotion and motivation. Emotion, 8(1), 34-46. doi:10.1037/1528-3542.8.1.34 السلسلسال

Ryan, R. M., \& Deci, E. L. (2000). Self-determination theory and the facilitation of intrinsic motivation, social development, and wellbeing. The American Psychologist, 55(1), 68-78. السلس

Salomons, T. V., Johnstone, T., Backonja, M. M., Shackman, A. J., \& Davidson, R. J. (2007). Individual differences in the effects of perceived controllability on pain perception: critical role of the prefrontal cortex. Journal of Cognitive Neuroscience, 19(6), 993-1003. doi:10.1162/jocn.2007.19.6.993 الس السلسلس

Smith, N. K., Cacioppo, J. T., Larsen, J. T., \& Chartrand, T. L. (2003). May I have your attention, please: Electrocortical responses to positive and negative stimuli. Neuropsychologia, 41(2), 171-183. doi:10.1016/s0028-3932(02)00147-1 السلسلسلسا

Valt, C., \& Sturmer, B. (2017). On the correct side of performance: Processing of internal and external signals in response speed evaluation. International Journal of Psychophysiology, 117, 26-36. doi:10.1016/j.ijpsycho.2017.04.005 المالسلسل

Van Boxtel, G. J. M., \& Brunia, C. H. M. (1994). Motor and non-motor components of the contingent negative variation. International Journal of Psychophysiology, 17(3), 269-279. doi:10.1016/0167-

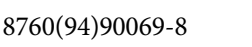

Van den Broeck, A., Vansteenkiste, M., De Witte, H., \& Lens, W. (2008). Explaining the relationships between job characteristics, burnout, and engagement: The role of basic psychological need satisfaction.

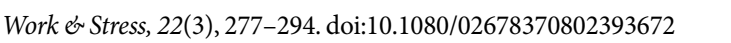
Van Rijn, H., Kononowicz, T. W., Meck, W. H., Ng, K. K., \& Penney, T. B. (2011). Contingent negative variation and its relation to time estimation: A theoretical evaluation. Frontiers in Integrative Neuroscience, 5:91. doi:10.3389/fnint.2011.00091 سلس

Vuillier, L., Whitebread, D., \& Szucs, D. (2015). ERP evidence of cognitive strategy change in motivational conditions with varying level of difficulty. Neuropsychologia, 70, 126-133. doi:10.1016/j.neuropsychologia.2015.02.025 سلس الس

Vuilleumier, P. (2005). How brains beware: neural mechanisms of emotional attention. Trends in Cognitive Sciences 9(12), 585-594. doi:10.1016/j.tics.2005.10.011 Шسلس

RECEIVED 09.06.2020 | ACCEPTED 04.05.2021 